\title{
Aspecto formativo dos dados das avaliações diagnósticas para os trabalhadores da gestão escolar nas escolas públicas de ensino médio do Estado do Ceará
}

\author{
Formative aspect of the data from the diagnostic evaluations for school management \\ workers in public high schools in the State of Ceará
}

\section{Aspecto formativo de los datos de las evaluaciones de diagnóstico para los trabajadores de la gestión escolar en las escuelas secundarias públicas del Estado de Ceará}

\section{Resumo}

Marcos Antonio Martins Lima ${ }^{1}$

Sandro Olímpio Silva Vasconcelos ${ }^{2}$

Suzana de Andrade Gonçalves Oliveira ${ }^{3}$

Francisca Camila Ciriaco da Costa ${ }^{4}$

A avaliação diagnóstica é um instrumento complementar, construído numa perspectiva formativa, que visa apontar níveis de proficiência em Matemática e Língua Portuguesa dos alunos das escolas de Ensino Médio no Estado do Ceará. O processo de apropriação dos resultados dessa avaliação inicia na coordenação pedagógica, de onde partem os norteamentos para as decisões curriculares na escola. Este trabalho investiga as percepções sobre esse tipo de avaliação pelos coordenadores em função da formação que esta lhes proporciona a partir do processo de apropriação, para gerar intervenções na escola. Buscou-se desenvolver a pesquisa a partir da metodologia Quadripolar (DE BRUYNE; HERMAN; SCHOUTHEETE, 1977), onde a partir dos princípios de Tyler, observou-se como essa apropriação influencia na percepção da composição do plano curricular, investigando essa relação a partir da entrevista semiestruturada com coordenadores escolares de escolas de Ensino Médio na região metropolitana de Fortaleza. Os dados foram tratados a partir da análise de conteúdo, com o auxílio do software de análise de dados qualitativos Atlas Ti. A pesquisa aponta para uma necessária compreensão do papel da gestão escolar na composição dos objetivos de aprendizagem na escola pública, como resultado da apropriação de avaliações como a Diagnóstica, onde confluem as formações inicial e continuada sempre em função das vivências de sua prática cotidiana.

Palavras-chave: Avaliação Diagnóstica; Tyler. Avaliação por objetivos; Gestão escolar.

\footnotetext{
Abstract

The diagnostic assessment is a complementary instrument, built from a formative perspective, which aims to identify levels of proficiency in Mathematics and Portuguese Language among

1 Universidade Federal do Ceará - UFC, Fortaleza - CE. E-mail: marcoslima@ ufc.br - https://orcid.org/00000001-5541-6220 - Lattes: http://lattes.cnpq.br/4480882123614278

2 Secretaria de Educação do Estado do Ceará, Fortaleza - CE. E-mail: sandrovasconcelos@alu.uern.br Orcid: https://orcid.org/0000-0001-8067-722X - Lattes: http://lattes.cnpq.br/4528721935318297

3 Universidade Federal do Ceará-UFC - Fortaleza-CE - E-mail: suzan.deandrade@ @otmail.com - Orcid: https://orcid.org/0000-0002-1474-6538 - Lattes: http://lattes.cnpq.br/6760669965311827

${ }^{4}$ Faculdade Unyleya - Fortaleza, CE. E-mail: camilaciriaco@ hotmail.com

Orcid: https://orcid.org/0000-0002-6111-8892 - Lattes: http://lattes.cnpq.br/0699810168745778
}

Revista Devir Educação, Lavras, vol.5, n2., p.224-248 jul./dez., 2021. 
students in high schools in the state of Ceará. The process of appropriation of the results of this evaluation begins in pedagogical coordination, from where the guidelines for curricular decisions in the school are taken. This paper investigates the coordinators' perceptions of this type of evaluation in terms of the formation it provides them from the appropriation process, to generate interventions in the school. The research was developed from the Quadripolar methodology (DE BRUYNE; HERMAN; SCHOUTHEETE, 1977), where from Tyler's principles, it was observed how this appropriation influences the perception of the curriculum plan composition, investigating this relation from semi-structured interviews with school coordinators of high schools in the metropolitan region of Fortaleza. The data were treated by content analysis, with the help of the qualitative data analysis software Atlas Ti. The research points to a necessary understanding of the role of school management in the composition of learning objectives in public schools, as a result of the appropriation of assessments such as the Diagnostic, where the initial and continuing education always converge according to the experiences of their daily practice.

Keywords - Diagnostic Assessment; Tyler. Evaluation by objectives; School management

\section{Resumen}

La evaluación diagnóstica es un instrumento complementario, construido desde una perspectiva formativa, que tiene como objetivo identificar los niveles de competencia en Matemáticas y Lengua Portuguesa de los alumnos de las escuelas secundarias del estado de Ceará. El proceso de apropiación de los resultados de esta evaluación se inicia en la coordinación pedagógica, de la que salen las directrices para las decisiones curriculares en la escuela. Este trabajo investiga la percepción de los coordinadores sobre este tipo de evaluación en vista de la formación que les proporciona desde el proceso de apropiación, para generar intervenciones en la escuela. La investigación se desarrolló a partir de la metodología Cuadripolar (DE BRUYNE; HERMAN; SCHOUTHEETE, 1977), donde a partir de los principios de Tyler, se observó cómo esta apropiación influye en la percepción de la composición del plan curricular, investigando esta relación a partir de la entrevista semiestructurada con coordinadores escolares de escuelas secundarias de la región metropolitana de Fortaleza. Los datos fueron tratados a partir del análisis de contenido, con la ayuda del software de análisis de datos cualitativos Atlas Ti. La investigación apunta a una necesaria comprensión del papel de la gestión escolar en la composición de los objetivos de aprendizaje en las escuelas públicas, como resultado de la apropiación de evaluaciones como la Evaluación de Diagnóstico, donde convergen la formación inicial y la formación continua, siempre según las experiencias de su práctica diaria.

Palabras clave: Evaluación diagnóstica; Tyler. Evaluación por Objetivos; Gestión Escolar

\section{Introdução}

Implementada no ano de 2017 para todos os alunos de Ensino Médio da rede pública, objetivando "oferecer um instrumento que trace um diagnóstico do desempenho dos estudantes, nas disciplinas de Língua Portuguesa e Matemática" (GOVERNO DO ESTADO DO CEARÁ, 2017) Esse desempenho é parametrizado a partir das "habilidades 
e competências previstas pela Matriz de Referência do Sistema Permanente de Avaliação da Educação Básica do Ceará - SPAECE” (id ibid). Desde sua implementação a avaliação é realizada em duas edições ao longo do ano letivo, em março e em agosto.

Nos dois momentos de aplicação os objetivos são primeiramente, verificar o nível de conhecimento adquirido e assim provocar uma intervenção pedagógica a fim de solucionar e corrigir déficits de aprendizagem de acordo com os níveis de proficiência, parametrizados como Muito Crítico, Crítico, Intermediário e Adequado. No segundo momento busca-se saber o quanto a intervenção pedagógica, motivada pelos resultados da primeira avaliação, conseguiu modificar os níveis de proficiência dos alunos. Isto posto, percebe-se que esse tipo de avaliação busca traçar um cenário de proficiência e provocar intervenções, a partir dos resultados, a fim de corrigir, reequilibrar e nivelar os participantes e continua, no processo, averiguando o quanto a intervenção obteve sucesso. De caráter formativo, essa avaliação busca provocar uma intervenção processual a partir do diagnóstico e propõe correções de rota na atividade educativa.

Apesar de repercutir nas práticas dos atores diretos da relação de aprendizagem, professor e aluno, os resultados da Avaliação Diagnóstica, na sua aprorpiação fornecem dados para a tomada de decisão sobre os percursos curriculares que a escola toma e esse campo, pertence, a princípio, aos coordenadores escolares. O primeiro contato com os resultados se dá nesse nível, que para efeito deste estudo, não é considerado do ponto de vista hierárquico, mas da responsabilidade em apresentar e conduzir a interpretação dos dados e a escolha dos caminhos pedagógicos a seguir com a comunidade escolar. Nessa perspectiva a questão da formação para a gestão pedagógica passa a ser objeto desta investigação. Como a apropriação de avaliações externas como a Avaliação Diagnóstica se reflete nas percepções sobre os fazeres destes atores e considera-se importante compreender como esse processo impacta a formação e a percepção destes acerca do planejamentode objetivos de aprendizagem.

Foi constituído como objetivo do trabalho identificar os como a Avaliação Diagnóstica é compreendida pelos gestores escolares em função de sua atuação pedagógica. Assim, estudar as bases epistemológicas da avaliação formativa, contextualizar as formas de implementação da Avaliação Diagnóstica e apropriação por parte da gestão escolar e discutir avanços e dificuldades dos gestores na sua comprensão e apropriação dos dados deste tipo de avaliação foram os objetivos específicos elencados 
para colaborar nessa empreitada.

Buscou-se pela pesquisa de campo, por meio virtual dadas as condições de isolamento social causadas pela pandemia de Covid-19, estudar a apropriação da avaliação Diagnóstica pelos coordenadores escolares, objeto deste estudo, recorrendo á entrevista semiestruturada para chegar aos dados, que foram tratados sob a ótica da análise de discurso, com o auxílio do software de análise de dados, Atlas Ti, versão 7. A partir deste ponto serão apresentados os quatro polos metodológicos (DE BRUYNE; HERMAN; SCHOUTHEETE, 1977), tratando o objeto desta pesquisa, a apresentação e discussão dos dados e as considerações finais.

\section{Polo epistemológico}

Este polo versa sobre a fundamentação epistemológica das teorias abordadas na pesquisa. Tem o propósito de promover informações que visam embasar os assuntos tratados através de aprofundamento filosófico acerca da temática desenvolvida. É a compreensão de maneira mais aprofundada dos assuntos abordados na pesquisa. A epistemologia "situa-se, portanto, de imediato, tanto numa lógica da descoberta quanto numa lógica da prova, o modo de produção dos conhecimentos interessa-lhe tanto quanto seus procedimentos de validação" (DE BRUYNE; HERMAN; SCHOUTHEETE, 1977, p. 43), assim, justifica os posicionamentos e através dela podemos constatar e explicar fatos.

Neste seguimento, para direcionar esta etapa, pautamos nas obras de Gaston Bachelard. O autor foi epistemólogo, crítico, cientista e poeta, nasceu em 1884 em Bar-surAube, França, zona rural. Trabalhou no serviço postal durante dez anos. Foi professor de Física de 1919 a 1930. Bachelard aborda a preocupação com a formação do conhecimento científico, autor em uma de suas obras apresenta a noção de obstáculo epistemológico como categoria central para compreender a processualidade da ciência.

[...] é no âmago do próprio ato de conhecer que aparecem, por uma espécie de imperativo funcional, lentidões e conflitos. É aí que mostraremos causas de estagnação e até de regressão, detectaremos causas de inércia às quais daremos nome de obstáculos epistemológicos (BACHELARD, 1996, p. 17).

É na busca do conhecimento, na tentativa de novas aprendizagens que podem surgir situações na qual possa acarretar estagnações e gerar conflitos. Assim, o que acreditamos saber, interfere no que deveríamos aprender. Para Bachelard (1996, p. 17), "O ato de conhecer dá-se contra um conhecimento anterior, destruindo conhecimentos mal estabelecidos, 
superando o que, no próprio espírito, é obstáculo à espiritualização" Logo, o desenvolvimento da ciência se aplica de maneira descontínua, onde é necessário romper o conhecimento anterior, desestruturá-lo para que possa ser construído um novo.

Dentre os obstáculos epistemológicos descritos por Bachelard, o primeiro a ser superado é da opinião, esta deve ser destruída, a ciência é totalmente contra. Bachelard (1996) diz que "A opinião pensa mal; não pensa: traduz necessidades em conhecimentos". Assim, no momento que designamos o objeto a partir da utilidade não há como conhecê-los. É necessário embasamentos plausíveis. A opinião em si, não acarreta veracidade aos fatos.

Nesta perspectiva, assim como a atividade científica, a atividade educativa apresenta obstáculos. Bachelard (1996), diz que dentro do campo educacional os obstáculos também são desconhecidos. É necessário que o docente compreenda que o espírito científico não se consolida através de repetições de conteúdo. O aluno já apresenta conhecimentos empíricos e estes devem ser reformulados para que se consolide e adquira novas aprendizagens. Neste contexto, cabe ao professor compreender o discente nas suas complexidades já que o ato avaliativo se insere como uma abordagem sistemática de atitudes que devem ser tomadas na ação avaliativa.

De acordo com Souza (2016), os apontamentos de Bachelard acerca da avaliação emerge quando faz crítica a precisão e o exagero empregado nos resultados divulgados por determinados pesquisadores no século XVIII, a crítica está ligada às técnicas adotadas pelos pesquisadores, já que estes buscam a precisão dos resultados, utilizam instrumentos que não medem o objeto de estudo e logo não permite avaliar os resultados apresentados.

Assim, avaliar não se constitui algo acabado, pronto e autossuficiente. Nesta perspectiva, as avaliações diagnósticas dentro do contexto do ensino médio objetivam a melhoria do ensino aprendizagem e logo o desenvolvimento acadêmico dos alunos. Logo, a educação exige que os professores repensem seus métodos e suas crenças, considerem todas as possibilidades experimentais, sejam capazes de pensar além, busquem possibilidades que possam ser implementadas no ensino e aprendizagem.

\section{Polo teórico}

Conforme Maciel (2009), o polo teórico possibilita a direção dos alinhamentos dos conceitos que serão apresentados em uma pesquisa, o saber ou os aparatos teóricos são de 
grande necessidade desde o seu início e deve se consolidar por meio do diálogo das partes e durante o percurso.

\section{Avaliação Educacional}

É interessante registrar neste estudo um breve histórico da avaliação para melhor compreender as definições referentes à avalição de programas educacionais nas organizações.

Embora uma disciplina de tenra atuação, a avaliação é uma prática antiga milenar que alcançou determináveis níveis de formalização desde as dinastias imperiais de países orientais como a China, Egito e Japão (Scriven,1991; Hartz,2009).

Conforme Lima (2005), a avaliação é tão antiga quanto o próprio homem. Para Serapion (2016) a avaliação tal como conhecemos hoje começou a se desenvolver com a revolução cientifica registrada nos séculos XVI e XVII, a qual se propõe uma diferença entre fatos e não apenas julgar valores.

Ainda segundo Lima (2007), percebe-se um maior interesse entre os pesquisadores e os profissionais da área acerca da avaliação educacional. A avaliação tem-se transformado em um dos caminhos mais complexos nas ciências da educação. É um campo do conhecimento que interage com outros campos refletindo, assim, o caráter político, histórico, econômico e social.

Marinelli e Lima (2010) afirmam que entre as diversas definições conhecidas de avaliação, autores como Worthen, Sanders, Fitzpatrick (2004) informam que a maioria prefere a proposta escrita por Scriven (1967), que define a avaliação como "julgar o valor de alguma coisa".

\section{Avaliação de Programas Educacionais}

Diante da aplicabilidade da prática avaliativa nas organizações, Lima (2007) registra que ela passou a ser aplicada nas organizações também mesmo diante das polemicas que surgem, devido à presença do subjetivismo, do intangível e do abstrato.

A avaliação de programas segundo Depresbiteris (1989) é uma forma especial de pesquisa criada para avaliar programas, normalmente são programas sociais para que haja melhorias, como reformas no bem-estar social, métodos de ensino inovadores, sistemas de distribuição de serviços de saúde, programas de treinamento de pessoal e afim. 
De acordo com Borges-Andrade, Abbad e Mourão (2012), os modelos de avaliação de programas podem ser genéricos ou específicos:

\section{Quadro 1: Modelos de avaliação}

\begin{tabular}{|c|c|}
\hline Genéricos & Específicos \\
\hline $\begin{array}{l}\text { Eles descrevem conjuntos de variáveis } \\
\text { relacionados ao processo que acontece. } \\
\text { Como por exemplo, o modelo de } \\
\text { Kirkpatrick (1978), que oferece referências } \\
\text { para a compreensão dos fenômenos } \\
\text { relacionados ao processo. }\end{array}$ & $\begin{array}{l}\text { São construídos com o intuito de testar relações entre um } \\
\text { conjunto de variáveis específicas e determinados } \\
\text { resultados dos programas no nível individual, no grupo de } \\
\text { trabalho ou nos níveis organizacional e extra } \\
\text { organizacional. }\end{array}$ \\
\hline
\end{tabular}

Fonte: Adaptado de Borges Andrade, Abbad e Mourão (2012)

Segundo Marinelli; Lima (2010 apud Silva, 1983, p. 1723) “A Avaliação supõe uma análise do desenvolvimento do programa, desde o planejamento, até o momento em que se possam constatar os efeitos produzidos pelo programa sobre os treinandos e o próprio sistema de treinamento, bem como nos resultados organizacionais".

\section{Ralph Winfred Tyler e os princípios básicos da avaliação}

Diante do contexto e afirmação da importância da avaliação no processo educacional, o educador americano Winfred Tyler foi um teórico e pensador de grande valor para a educação, principalmente no que se diz à avaliação e desenvolvimento do currículo estabelecido para o processo de ensino e aprendizagem posto.

Ralph W. Tyler (1902-1994) foi um educador nascido na América do Norte, Nasceu no dia 22 de abril de 1902, em Chicago. Ele desenvolveu um modelo de avaliação de currículos e programas educacionais com alvo nos objetivos. No ano de 1921, aos dezenove anos recebeu o seu diploma de bacharel pelo Doane College, em Creta, Nebraska. No ano de 1954, Tyler foi nomeado diretor-fundador do Centro de Estudos Avançados em Ciências Comportamentais e esteve nessa função até o ano de 1967. (ALVES; SARAIVA, 2013).

Anterior às reflexões e registros de Tyler, a avaliação era posta meramente como uma questão técnica para medir os resultados obtidos nos processos de aprendizagem que serviam sempre para comparar grupos e grupos de alunos. A partir de Tyler, a avaliação perpassa para uma visão mais ampla contemplando uma descrição de até que pontos os alunos do processo atingiam os objetivos definidos. A avaliação considerando apenas a quantificação passou a ser uma das maneiras de se avaliar, não subsistindo em si mesma. (ALVES; SARAIVA, 2013). 
Diante disso, "a fim de estudar de maneira sistemática e inteligente um programa educacional, devemos começar por determinar claramente quais são os objetivos educacionais colimados" (TYLER, 1976, p.3). Sendo assim, as noções de educação e de de se avaliar estão intrinsecamente ligadas aos objetivos. O modelo tyleriano deu um lugar de destaque à avaliação que é vista como "um processo de estabelecimento da comparação entre desempenhos e a concretização de objetivos instrucionais pré-definidos" (VIANNA, 2000, p.26).

No início da obra Princípios Básicos do Currículo e Ensino (1949), Tyler aponta quatro pontos fundamentais que exigem um olhar mais atencioso quando se vai criar quaisquer currículos ou planos educacionais, quais sejam:

1. Que objetivos educacionais deve a escola procurar atingir?

2. Que experiências educacionais podem ser oferecidas que tenham probabilidade de alcançar estes propósitos?

3. Como organizar eficientemente essas experiências educacionais?

4. Como podemos ter certeza de que esses objetivos estão sendo alcançados? (TYLER, 1976, p.2)

O pensamento de Tyler foi embasado na Administração Científica orientada para a sistematização, a eficiência e a produtividade. Diante disso, Tyler se referiu aos programas educacionais como programas em que muitas vezes os objetivos não são bem definidos, no entanto, considera que os professores atuantes possuem alto poder de conhecimento e cultura, embora muitos não se apropriam da concepção clara das metas. (TYLER, 1976).

\section{Polo morfológico}

A Avalação diagnóstica, como avaliação formativa, propõe uma mudança de comportamento do aluno à med-ida em que, conhecendo suas dificuldades e limitações quanto às competências e habilidades requisitadas para a resolução de situações problema, possa avançar, com a orientação do professor, para a melhoria de seu aprendizado. O contato com os resultados da avaliação se dá a partir do conhecimento de seu nível de desenvolvimento e das características definidas pelos indicadores muito crítico, crítico, intermediário e adequado, consignados a partir dos padrões de desenvolvimento do SPAECE. 
pedagógicas mais especializadas, de modo a garantir o desenvolvimento das habilidades necessárias ao sucesso escolar, evitando, assim, a repetência e a evasão. (CAED, 2018, p. 1)

A Avaliação Diagnóstica baseia-se na série histórica de outro sistema de avaliação criado no Ceará, o Sistema Permanente de Avaliação da Educação Básica, SPAECE. Criado em 1992, é uma avaliação longitudinal, censitária, "externa em larga escala, que avalia as competências e habilidades dos alunos do Ensino Fundamental e do Ensino Médio, em Língua Portuguesa e Matemática.” (GOVERNO DO ESTADO DO CEARÁ, 2017). As informações coletadas permitem acompanhar a progressão de "desempenho de aprendizagem do aluno ao longo do tempo" (id ibid). A composição dos descritores que parametrizam a proficiência dos alunos baseia-se na Matriz Curricular de Ensino e "contempla apenas aquelas habilidades consideradas fundamentais e possíveis de serem avaliadas, sobretudo em testes de múltipla escolha" (CAED/UFJF, 2018, p 1).

A cada resultado avaliativo é criada, para os descritores avaliados, uma proposta didática que analisa, explica, trabalha e avalia o descritor visando a melhoria do desempenho dos alunos. Essa proposta pode basear todas as intervenções que a escola ou o professor podem fazer durante o ano letivo. Sendo implementada duas vezes ao ano, com resultados parametrizados e transpostos em indicadores e com propostas de intervenção para a melhoria da aprendizagem, pode-se caracterizar a Avaliação Diagnóstica como uma avaliação de propósito formativo. A avaliação formativa visa dar indicações da posição em que os avaliados se encontram em relação ao que se espera da aprendizagem para aquele nível/período de estudos o que implica em dar feedback dessa posição na perspectiva de indicar seus pontos fortes e fracos, encorajar e orientar sua aprendizagem (GREGO, 2013).

A composição do polo morfológico implica em apresentar um modelo, uma configuração, uma arquitetura (DE BRUYNE; HERMAN; SCHOUTHEETE, 1977), de onde serão buscadas as relações causais, as conexões entre o objeto de estudo e os fatores externos e internos. Nesse estudo sobre a Avaliação Diagnóstica é observada através da avaliação dos objetivos formativos de Tyler (1973). O autor centraliza sua avaliação nos avanços e nos rendimentos dos alunos, nesse sentido um programa educacional terá sua eficiência medida pelo sucesso de seus alunos em alcançar os objetivos de aprendizagem estabelecidos. Nesse ponto, elenca, para a avaliação do currículo, a clareza nos objetivos de aprendizagem, seu nivelamento e definição em termos comportamentais. Esses objetivos precisam ser compreendidos como comportamentos que advém das situações propostas para atingi-los. A 
coleta de dados sobre esses objetivos se dá por meio de instrumentos adequados, construídos ou adaptados para essa finalidade e a elaboração dos critérios para a interpretação desses resultados (DEPRESBITERIS, 2000).

Quadro 2: Elaboração dos princípios de Tyler (1973)

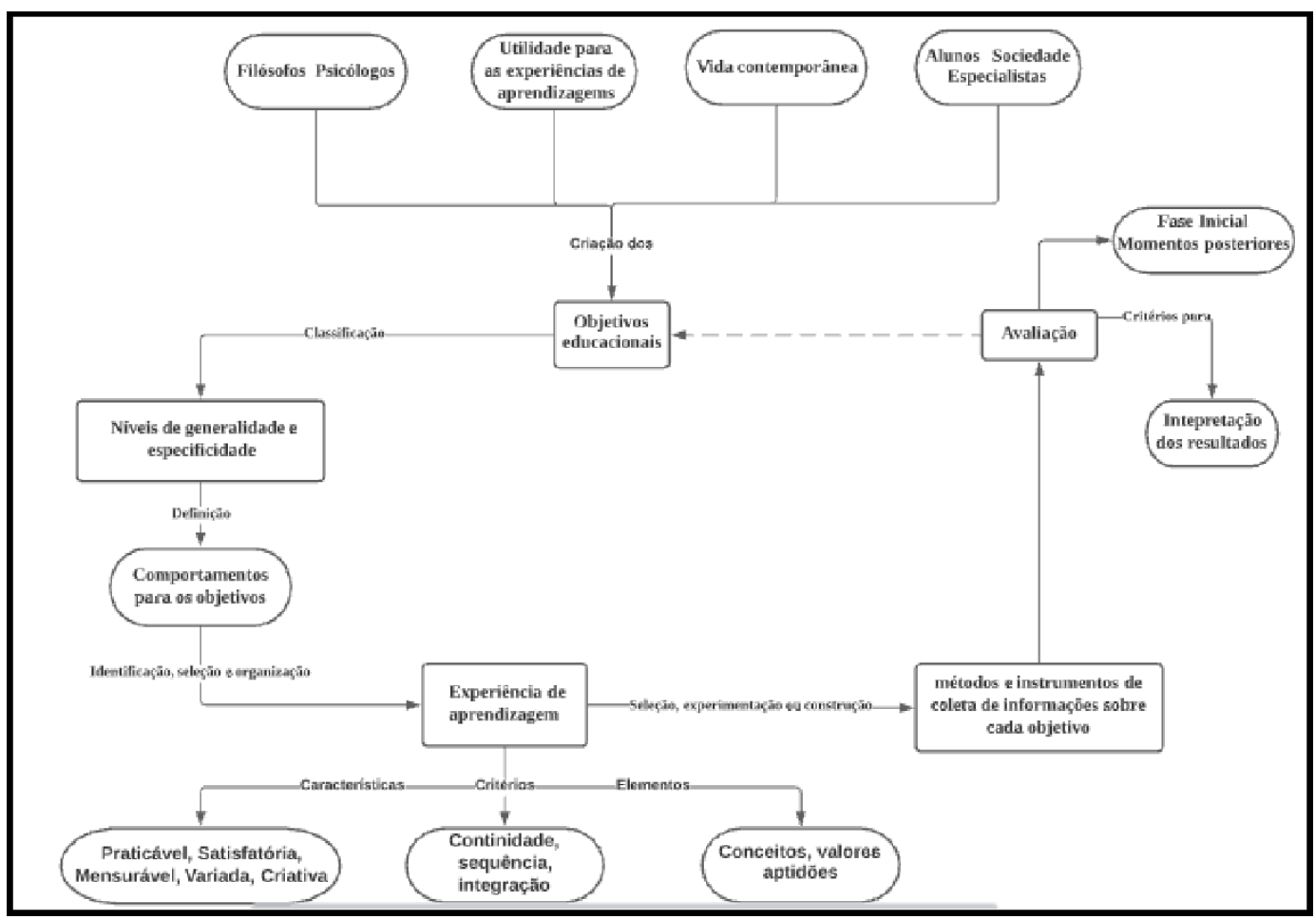

Fonte: Elaborado pelos autores.

O quadro 2 apresenta o processo de elaboração dos princípios do modelo de Tyler (1973) para a elaboração do currículo. É importante salientar que na avaliação dos objetivos educacionais, a identificação do posicionamento dos alunos indicarão seus pontos fortes e fracos de acordo com os objetivos de aprendizagem elencados no currículo, o que compreende também a avaliação da eficiência do programa da escola com seus pontos críticos que devem ser utilizados para melhorá-la, aperfeiçoá-la (ALVES; SARAIVA, 2013).

A Avaliação Diagnóstica realizada na rede estadual do Ceará baseia-se na Matriz Curricular de Ensino, onde "contempla apenas aquelas habilidades consideradas fundamentais e possíveis de serem avaliadas, sobretudo em testes de múltipla escolha" (CAED/UFJF, 2018). Ao final do período avaliativo os dados da avaliação são fornecidos às escolas por meio do Sistema Online de Avaliação, Suporte e Acompanhamento Educacional, SISEDU, plataforma que fornece os dados individuais, por turma e por escola contendo percentual de acertos por descritores e nível de proficiência. Essa avaliação é apropriada na 
escola, em primeiro lugar pela coordenação escolar, onde os resultados são analisados e, posteriormente, discutidos na perspectiva da situação de aprendizagem dos alunos. Somente após essa discussão e análise é que os resultados são apresentados à comunidade escolar. Objetiva-se neste trabalho discutir Avaliação Diagnóstica na percepção dos coordenadores, tendo em vista suas atribuições quanto à elaboração do programa de ensino da escola. $\mathrm{O}$ modelo de Tyler (1973) será empregado visando analisar as ações apontadas pelos coordenadores na perspectiva da avaliação dos objetivos de aprendizagem, tendo como base os indicadores de proficiência da Avaliação Diagnóstica.

\section{Polo técnico}

O Polo Técnico faz parte do processo metodológico. É a exposição do percurso na busca do saber científico, para identificar as configurações da pesquisa acadêmica. A metodologia utilizada é de natureza qualitativa, caracterizada pela abordagem exploratória. Uma pesquisa de campo, com a observação da ferramenta de apresentação dos resultados da Avaliação Diagnóstica e coleta de dados por meio de entrevista semi-estruturada, seguida da análise de conteúdo dos achados. A análise de conteúdo consiste em "um conjunto de técnicas de análise das comunicações, que utiliza procedimentos sistemáticos e objetivos de descrição do conteúdo das mensagens" (BARDIN, 2006, p. 38). É o enriquecimento da pesquisa bibliográfica realizada, permitindo que os documentos pesquisados possam colaborar na busca por respostas às questões da pesquisa, tornando possível identificar o que os pesquisadores de determinada área estão afirmando a respeito do tema em estudo (VERGARA, 2005).

Compreende-se que a pesquisa social não acontece isoladamente, visto que "o ato de pesquisar traz em si a necessidade do diálogo com a realidade a qual se pretende investigar e com o diferente, um diálogo dotado de crítica, canalizador de momentos criativos" (JOSÉ FILHO, 2006, p.64). Esse diálogo requisita uma aproximação com o objeto da pesquisa de modo a perceber sua dinâmica e complexidade. além disso, há na pesquisa uma troca dinâmica de conhecimentos de tal forma que o objeto e os sujeito já não serão mais os mesmos, mas serão transformados, um pelo olhar e abordagem do sujeito pesquisador e o outro pela nova compreensão do todo e das partes que compõem o fenômeno estudado.

A pesquisa de campo corresponde à observação, coleta, análise e interpretação de fatos e fenômenos que ocorrem nos ambientes de vivência. O campo, neste trabalho, considerando a situação de ensino remoto provocada pela pandemia de covid-19, é o meio virtual, onde 
acontecem as atividades e por onde foram aplicadas as Avaliações Diagnósticas. A opção pela percepção dos coordenadores escolares como objeto de investigação se deu pela proximidade com os dados e necessária compreensão dos resultados a fim de organizar a rotina escolar dentro do programa curricular de cada escola. No Ceará, convivem três perfis de oferta educacional, com carga horária e finalidades distintas: a escola regular, com três turnos de oferta diária, a escola de tempo integral com um turno de $9 \mathrm{~h}$ de oferta diária e a escola profissionalizante com $9 \mathrm{~h}$ diárias de oferta. Participaram da pesquisa coordenadores de escolas regulares e escolas de tempo integral.

O instrumento de coleta de dados escolhido foi a entrevista semi-estruturada, composta a partir dos objetivos específicos deste trabalho. Objetivou-se neste trabalho Identificar os como a avaliação diagnóstica é compreendida pelos gestores escolares em função de sua atuação pedagógica. Para isso buscou-se especificamente estudar as bases epistemológicas da avaliação formativa, contextualizar as formas de implementação da avaliação diagnóstica e apropriação por parte da gestão escolar e discutir avanços e dificuldades dos gestores na sua compreensão e apropriação dos dados da avaliação diagnóstica.

O quadro 3 apresenta os objetivos específicos relacionados com as questões da entrevista e com os princípios de Tyler (1993). As entrevistas foram realizadas por meio virtual com gravações de áudio enviadas por meio eletrônico de mensagens, posteriormente foram transcritas e analisadas com o uso do software Atlas Ti. Os achados foram analisados à luz de Bardin (2006), estruturada em três fases: pré-análise; exploração do material; e tratamento dos resultados, dos quais também fizeram parte da inferência e da interpretação.

Quadro 3: elaboração das questões da entrevista à luz do quadro referencial de Tyler (1993).

\begin{tabular}{|c|c|c|}
\hline $\begin{array}{l}\text { Objetivos } \\
\text { specíficos }\end{array}$ & Questões & $\begin{array}{l}\text { Elaboração do currículo } \\
\text { (Tyler) }\end{array}$ \\
\hline
\end{tabular}

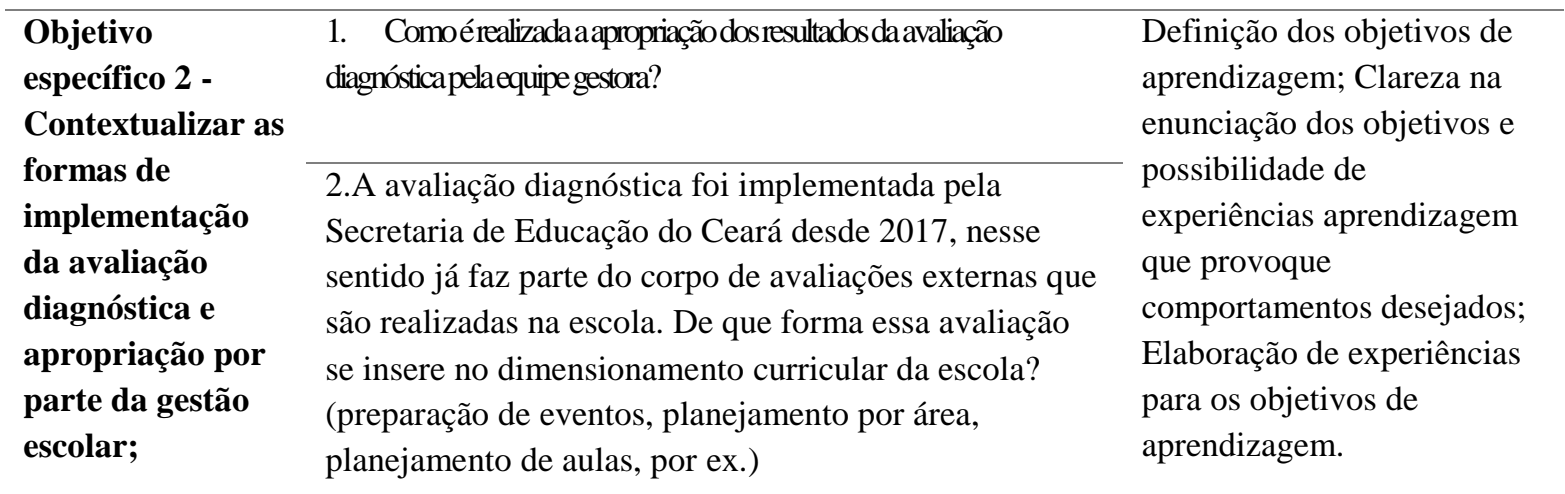

Revista Devir Educação, Lavras, vol.5, n2., p.224-248 jul./dez., 2021. 
3. Qual a repercussão que a avaliação diagnóstica tem na tomada de decisão sobre a elaboração do planejamento curricular da escola?

4. Na organização curricular da escola, como a coordenação escolar consegue orientar os objetivos de aprendizagem em função dos resultados das avaliações diagnósticas? A escola avalia seu alcance?

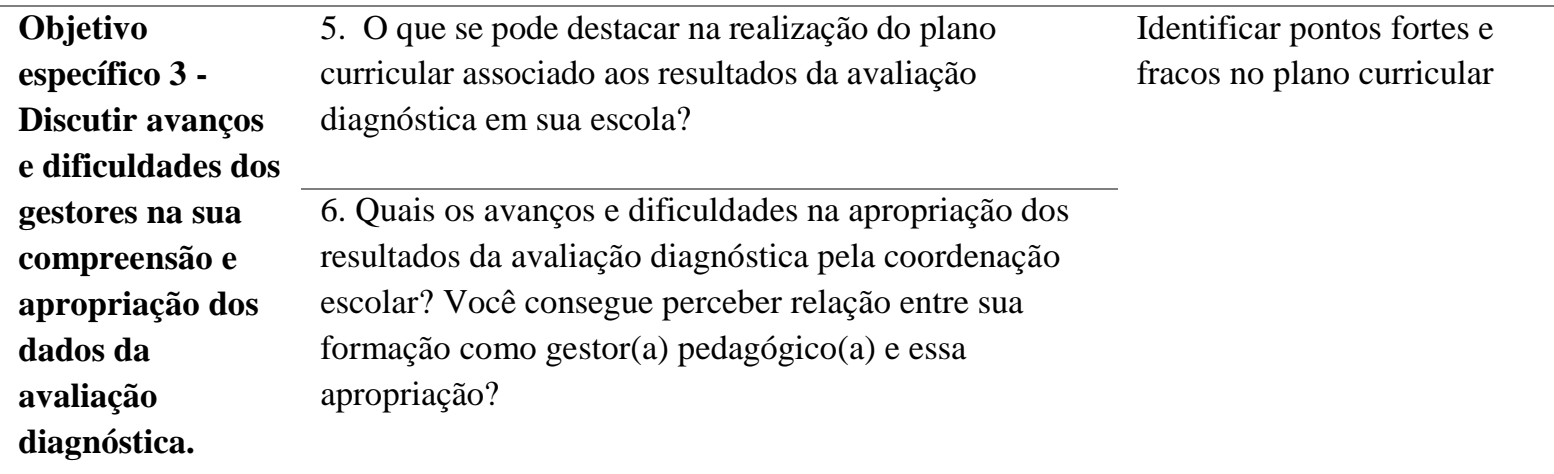

Fonte: Elaborado pelos autores.

É importante ressaltar que os achados da entrevista geraram relações não previstas no instrumento de análise. A codificação contemplou a transcrição, criação dos documentos primários por bloco de questões, interpretação dos textos, codificação e criação de famílias de códigos e mapas semânticos. As percepções dos respondentes foram elencadas nas relações dos mapas semânticos, desse modo, cada código criado vincula-se aos sentidos dados nas respostas e nessa perspectiva foram geradas as relações entre os códigos. O uso de softwares de análise de dados qualitativos contribui para um bom gerenciamento dos dados, sua indexação, recuperação de segmentos e, inclusive o compartilhamento de códigos por bases diferentes, encorajando sua análise exploratória (LAGE; GODOY, 2008) .

A construção dos mapas de relações, ou mapa semântico no caso do Atlas Ti, possibilita a interpretação do pesquisador, com isso, colabora para a prática dos distanciamentos e aproximações com o objeto de estudo, para a abstração e síntese, bem como para a familiarização com suas particularidades para estabelecer uma análise mais aproximada desses dados (LAGE; GODOY, 2008).

O software Atlas Ti apresenta relações nativas de pertença, associação, e causa e efeito (FRIESE, 2019). Neste trabalho foi preciso editá-las - e até mesmo criá-las - para atender as necessidades de análise do conteúdo apresentado, cumprindo a necessária intervenção dos sujeitos na análise dos dados, não atribuindo ao software a tarefa de realizar as relações sem

Revista Devir Educação, Lavras, vol.5, n2., p.224-248 jul./dez., 2021. 
as intervenções do pesquisador, num exercício de distanciamento e aproximação com os materiais coletados, sem comprometer o distanciamento necessário de seu objeto de estudo (LAGE; GODOY, 2008).

\section{Resultados e discussão}

Para este trabalho foram convidados a participar coordenadores escolares da rede estadual de ensino. Após a aplicação da avaliação diagnóstica esse grupo de trabalhadores da educação é o primeiro a ter contato comos resultados, devendo partir deles as iniciativas para a realização das reuniões de apropriação dos resultados e decisões acerca das iniciativas que a escola deve tomar. Nesse sentido, a coordenação é o primeiro filtro pelo qual os resultados passam e depende dela a mobilização da escola em função da melhoria das defasagens detectadas.

Os coordenadores escolares convidados a participar da pesquisa atuam em escolas dos municípios de Fortaleza e Caucaia. No período em que foram entrevistados estavam em escala de revesamento por causa das férias escolares, dependendo então de sua disponibilidade, mais ainda a participação respondendo às perguntas descritas no polo técnico. Participaram desta pesquisa coordenadores de quatro escolas estaduais na administração da Coordenadoria Regional de Desenvolvimento da Educação 01, CREDE 01, situadas em Maracanaú e em Caucaia. Duas escolas são regulares, e duas passaram ao regimede tempointegral a partir de 2017.

O quadro 04 apresenta os resultados dessas escolas no SPAECE na série que vai de 2012 a 2019. É importante para a compreensão dos documentos pesquisados e das entrevistas realizadas conhecer esses resultados, mesmo que sucintamente, porque sua observação ajuda a perceber as mudanças ocorridas nos desempenhos em Língua Portuguesa e em Matemática a partir dos indicadores da Matriz de referência do SPAECE, da qual são retiradas as matrizes para a elaboração da Avaliação Diagnóstica. Para melhor compreender a situação das escolas apresentamos os indicadores de desempenho. Segue-se uma pontuação que ajuda a posicionar o aluno em situações de desenvolvimentoda aprendizagem.

Os Padrões de Desempenho são categorias definidas a partir de cortes numéricos que agrupam os níveis da Escala de Proficiência, com base nas metas educacionais estabelecidas pelo SPAECE. Esses cortes dão origem a quatro Padrões de Desempenho - Muito crítico, Crítico, Intermediário e Adequado -, os quais apresentam o perfil de desempenho dos alunos (CAED/UFJF, 2018, p. 1).

Revista Devir Educação, Lavras, vol.5, n2., p.224-248 jul./dez., 2021. 
Os cortes numéricos são feitos em uma escala de 500 pontos com a seguinte divisão: Nível muito crítico com até 225 pontos em Língua Portuguesa e 250 em matemática; Nível crítico, entre 226 e 275 pontos para Língua Portuguesa e entre 251 e 300 para Matemática; Nível intermediário, entre 276 e 325 pontos em Língua Portuguesa e entre 301 e 350 pontos em Matemática e, finalmente, nível adequado para pontuações acima de 325 pontos em Língua Portuguesa e acima de 350 pontos em Matemática. Esses indicadores são apresentados como um conjunto de habilidades que deveriam desenvolver para solucionar as questões apresentadas, redundando em um nível de desempenho escolar. Esses instrumentos de categorização buscam "contribuir para a construção de representações cognitivas sobre o real" (FERREIRA; TENÓRIO, 2010, p. 74).

Quadro 4: Informação do SPAECE das escolas participantes da pesquisa em Matemática e Língua Portuguesa de 2012 à 2019.

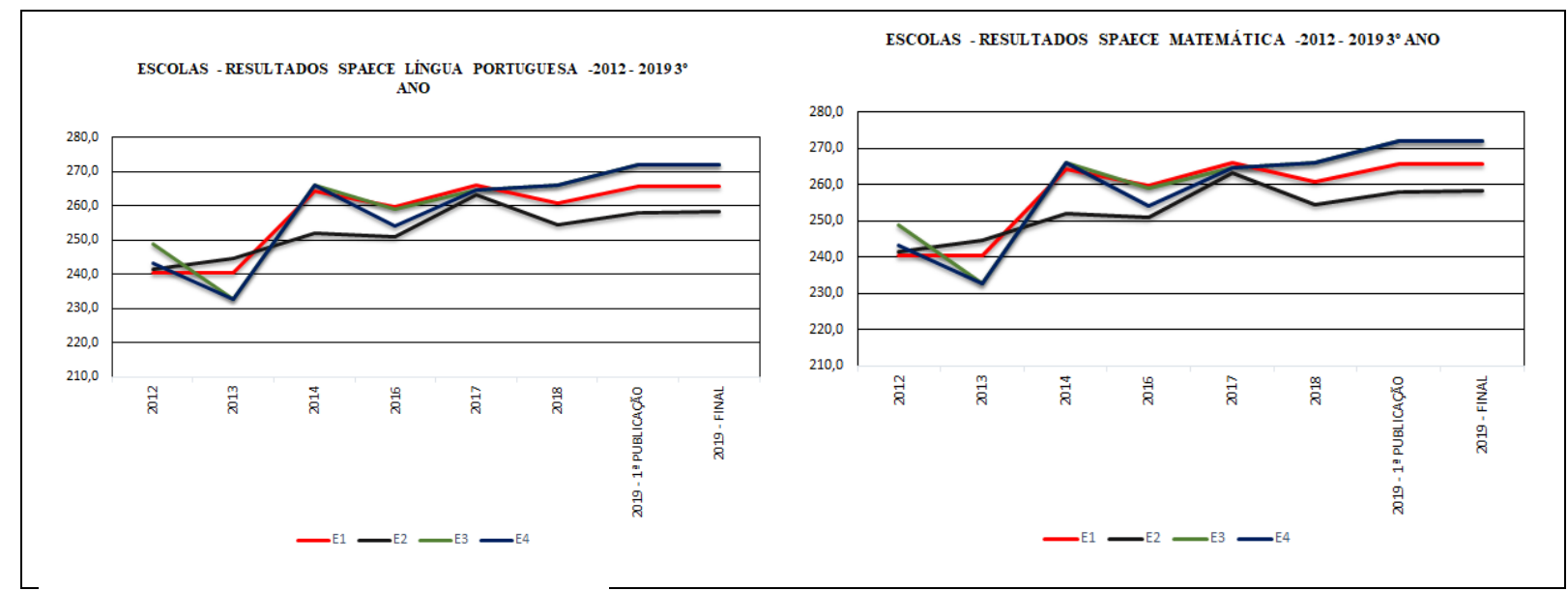

Fonte: Elaborado pelos autores a partir de CAED/UFJF (2018).

Percebe-se no quadro 4 que em Matemática e em Língua Portuguesa os níveis de desempenho oscilam entre Muito Crítico e Crítico, sendo este último o nível alcançado pelas escolas nos dois últimos anos da contagem. Essa perspectiva ajuda a compreender que os planos curriculares das escolas tendam a buscar corrigir essas diferenças e, nesse sentido, elaborem seus objetivos de aprendizagem, visto que "os padrões de desempenho estudantil, nesse sentido, são balizadores dos diferentes graus de realização educacional alcançados pela escola" (CAED/UFJF, 2018).

A avaliação diagnóstica, que é criada a partir da matriz de referências do SPAECE, visa traçar um perfil dos alunos em relação ao desempenho em Matemática e Língua Portuguesa ao longo do Ensino Médio. É aplicada duas vezes ao ano. As provas são digitais e precisam ser aplicadas em computadores ou aparelho celular. $\mathrm{O}$ acesso à essas provas é dado 
pelo portal Aluno Online, do Governo do Estado do Ceará, onde cada aluno participante é identificado por sua matrícula. Os gabaritos são computados no Sistema Online de Avaliação, Suporte e Acompanhamento Educacional, SISEDU. Este sistema foi implementado em 2018 para dar maior celeridade à chegada dos resultados às escolas para que as intervenções necessárias fossem realizadas. Sua finalidade é "melhorar a avaliação e o acompanhamento da aprendizagem do aluno e fornece ao professor um rol de situações didáticas que possibilitem incursões em sala de aula para tentar reverter insucessos apresentados nos resultados da avaliação" (PENHA et al., 2019, p. 1126).

Até aqui foram apresentados os dados do SPAECE das escolas cujos coordenadores participaram da pesquisa, as características dos cortes relativos aos indicadores apontados nessa avaliação, que serve de matriz para a Avaliação Diagnóstica. Além disso, os níveis de desempenho em Língua Portuguesa e Matemática foram discriminados, bem como apresentou-se o sistema de monitoramento da avaliação. Deste ponto em diante seguirá a apresentação dos quadros referentes às entrevistas e sua análise à luz de Tyler (1973).

É importante resgatar do Polo Técnico a relação entre as questões utilizadas na entrevista com os princípios de Tyler (1973) para a avaliação e elaboração do currículo. As questões buscaram relacionar a percepção dos coordenadores escolares sobre a apropriação da Avaliação Diagnóstica implementada duas vezes ao ano na escola pública estadual cearense na perspectiva da elaboração de objetivos de aprendizagem para a correção das defasagens de aprendizagem em Língua Portuguesa e Matemática verificadas por essa mesma avaliação externa. Foram elencados dois objetivos específicos: Contextualizar as formas de implementação da avaliação diagnóstica e apropriação por parte da gestão escolar e discutir avanços e dificuldades dos gestores na sua compreensão e apropriação dos dados da avaliação diagnóstica.

A análise das entrevistas resultou na criação de cinco famílias de códigos: adequação curricular, acompanhamento, dificuldades e desafios, formação dos coordenadores e apropriação. Cada família será apresentada abaixo com sua descrição e análise de relações. A organização das famílias origina-se nas relações apresentadas pelos respondentes com os objetivos específicos deste trabalho. Não se trata, então de apresentar e analisar as respostas a cada pergunta, mas desvelar, nas construções das argumentações destes, suas percepções. Os códigos aparecem nos quadros com sua descrição, que é a forma como emergiram da análise dos textos. São relacionados, de acordo com essa compreensão, uns com os outros.

Revista Devir Educação, Lavras, vol.5, n2., p.224-248 jul./dez., 2021. 
A família Acompanhamento corresponde à visão sobre o histórico das aplicações das avaliações externas e os resultados da escola. As atitudes, planejamentos, desafios e tomadas de decisão acerca das realidades das escolas e as relações entre os códigos criados.

Figura 1: Família acompanhamento

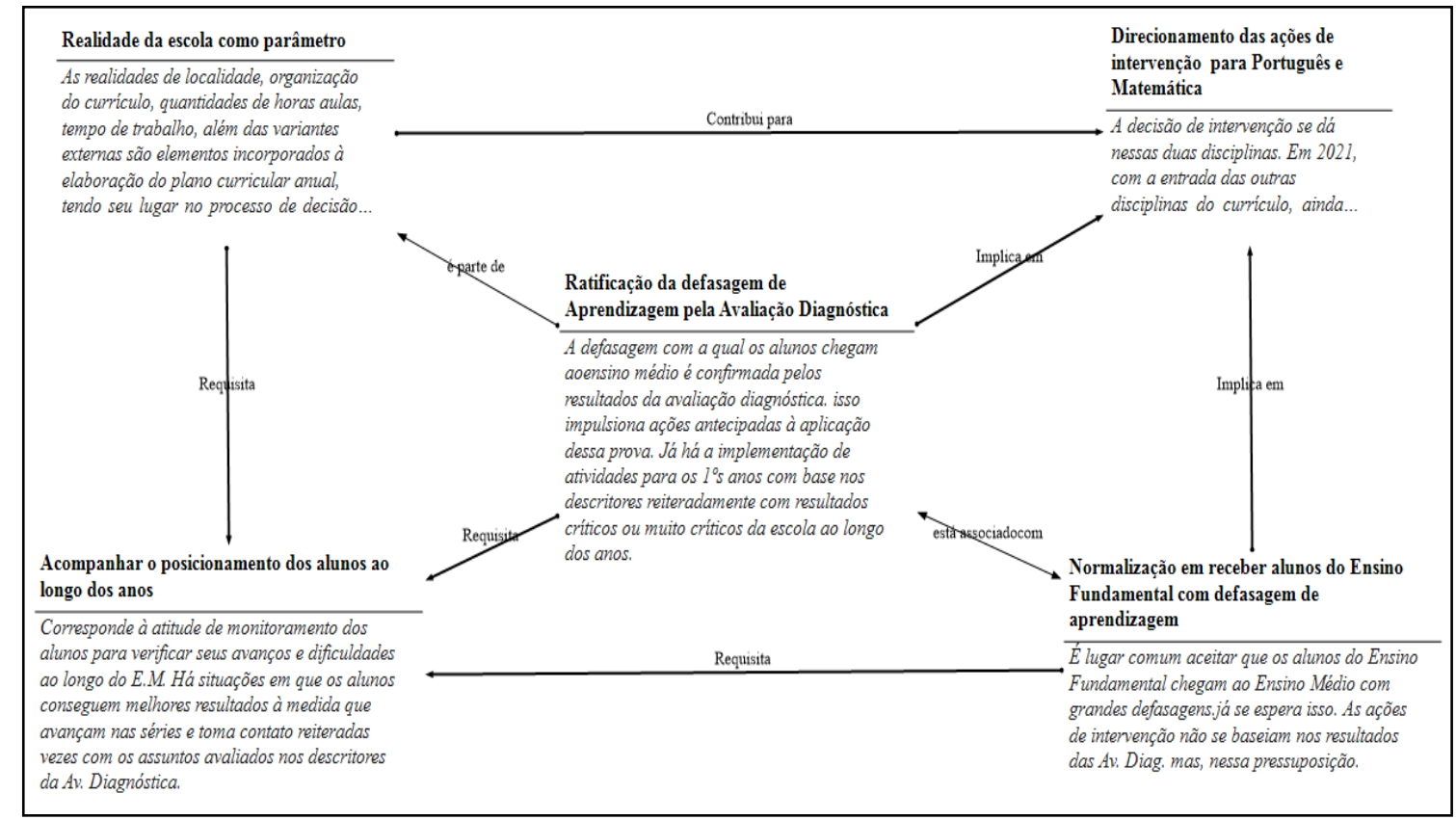

Fonte: Elaborado pelos autores com software Atlas Ti.

A entrada de alunos no Ensino Médio já com uma defasagem de aprendizagem é entendida dentro da normalidade pelas escolas. Os níveis de desempenho são explicados nos descritores, onde alunos, turmas e escola são posicionados. Ao relacionar a normalização da defasagem de aprendizagem dos alunos ingressantes com o direcionamento das ações de intervenção, mostra-se que um dos objetivos da Avaliação Diagnóstica se cumpre na mobilização de esforços adequando o currículo para buscar corrigir essas distorções. Nessa perspectiva cabe questionar os motivos pelos quais essas defasagens ainda não são diminuídas nas medições posteriores e que fatores podem interferir e/ou contribuir para a melhoria da aprendizagem.

Tyler (1973) aponta para a definição de objetivos de aprendizagem em quatro campos: a discussão com os alunos, a consulta aos especialistas, estudo da vida contemporânea e a utilidade na seleção das experiências de aprendizagem. Se a decisão por adequar o programa das disciplinas para ajudar a corrigir essas defasagens já no início do ano letivo leva em consideração essa normalidade, percebida inclusive nos resultados do SPAECE apresentados no quadro 3, possivelmente precisa-se discutir as estratégias pelas quais se quer atingir esse 
objetivo, se no campo da elaboração dos objetivos, ou na definição das metas, ou mesmo na criação de situações de aprendizagem. Acerca disso Tyler (1993) afirma que é necessário ter clareza nos objetivos a serem alcançados e o envolvimento da equipe de professores deve implicar em conhecimento das metas a serem alcançadas, não definidas em números.

Outro aspecto importante ressaltado pelos respondentes é a compreensão das realidades da escola sendo usada como parâmetro para a elaboração do plano curricular. É nesse sentido que as dificuldades cognitivas se encontram com as variantes externas e podem ser estudadas e repercutidas na organização da escola, tanto dos objetivos de aprendizagem, quanto das situações propostas para atingir esses objetivos.

A percepção da necessidade de acompanhar o posicionamento dos alunos ao longo do Ensino Médio implica em desenvolver uma atitude de monitoramento não apenas dos resultados, mas também das relações entre os objetivos, situações de aprendizagem e sua implementação. Nesse ponto da avaliação dessas ações da escola, não se encontra mais no campo da intervenção, passa a ter um caráter mais propositivo, implicando em avaliar os processos e isso é uma dificuldade apontada pelos respondentes.

Figura 2: Família Adequação curricular.

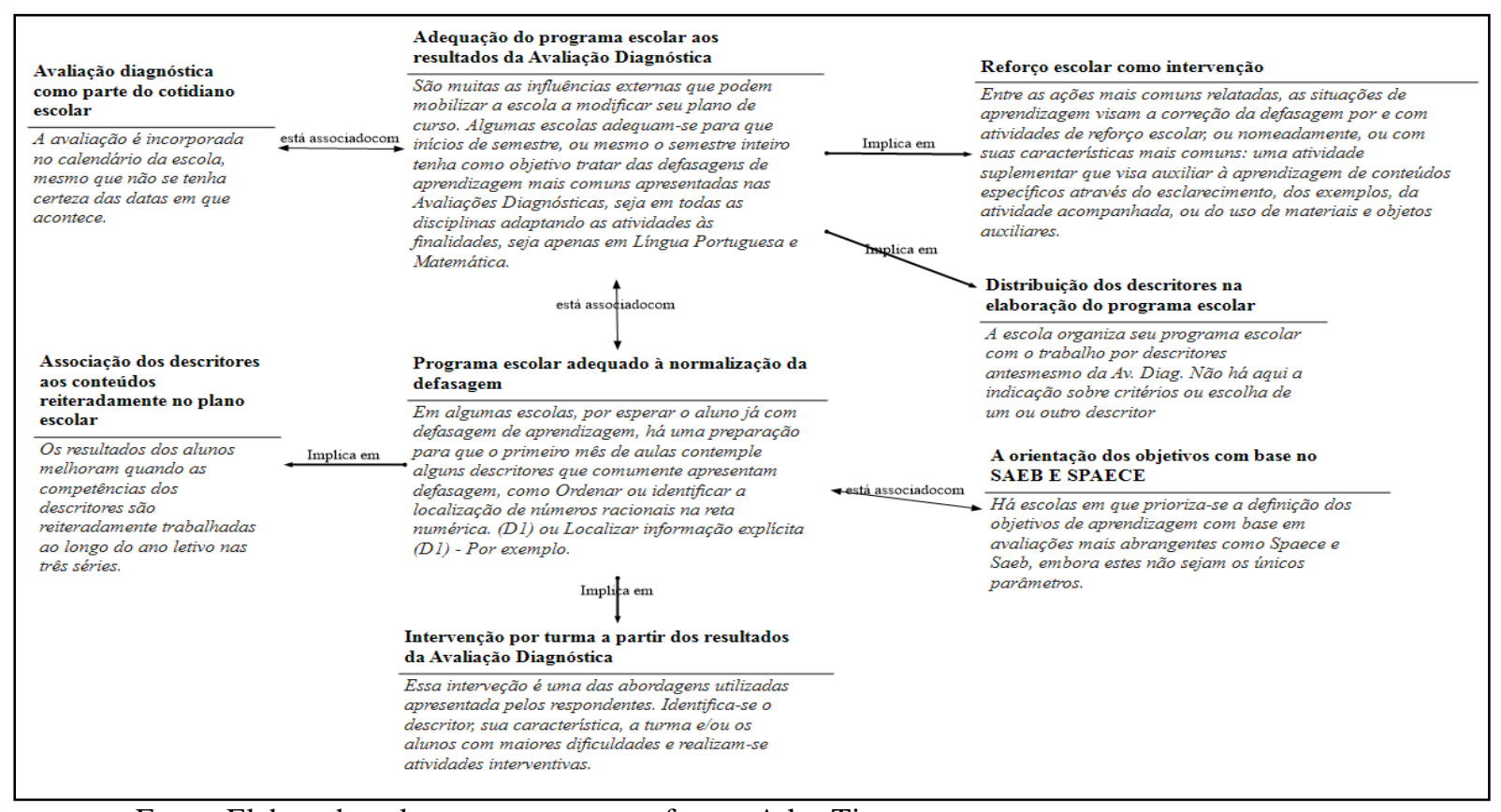

Fonte: Elaborado pelos autores com o software Atlas Ti

A família adequação curricular emergiu das relações entre a normalização da defasagem de aprendizagem dos ingressantes no Ensino Médio e os processos de decisão sobre as estratégias para a correção das defasagens de aprendizagem. Apesar de sua 


\section{OO DEVIR EDUCAÇÃO}

ISSN: 2526-849X

implementação há pouco tempo em relação ao SPAECE, a Avaliação Diagnóstica é apresentada como parte do cotidiano escolar. Essa incorporação ao calendário associa-se às adequações do programa curricular da escola, inclusive com a adaptação das disciplinas a atender as necessidades de atingir os objetivos de aprendizagem definidos. Cabe aqui discutir a necessidade de se desenvolver a apropriação das finalidades formativas da Avaliação Diagnóstica pela coordenação pedagógica.

A avaliação subsidia o posicionamento do objeto avaliado em relação ao seu lugar ideal (LIMA, 2005), sendo a distância entre esses pontos, em situação de defasagem de aprendizagem, tratada com a elaboração de um plano de ação para levar o aluno a corrigir essa diferença. A partilha dos resultados e de seus significados com os alunos é importante no sentido de dar a compreender os parâmetros utilizados e apontar as fraquezas em relação a estes. Além disso, a instituição precisa relacionar os objetivos educacionais, as experiências de aprendizagem e a análise dos resultados (TYLER, 1973), (ALVES; SARAIVA, 2013). Em relação aos resultados da Avaliação Diagnóstica algumas situações requerem um olhar mais acurado e denotam carência formativa em relação à elaboração de um plano curricular adaptado. A distribuição dos descritores por turma sem uma análise de sua pertinência ou maior compreensão de como atingir seus objetivos de aprendizagem, a ênfase no reforço escolar como forma de diminuir as defasagens são iniciativas que apontam essa carência formativa.

A Avaliação Diagnóstica fornece a cada edição material estruturado para auxiliar aos professores de Matemática e Língua Portuguesa "para dar a possibilidade de trabalhar conteúdos e habilidades que o aluno não tenha conseguido desenvolver dentro do seu nível de conhecimento ao longo do seu processo formativo até o momento da avaliação" (PENHA, 2019, p. 1130). Isso contribui para que haja uma intervenção mais qualificada, porém, redimensionar essas propostas estruturadas em um currículo, perpassando todas as disciplinas é um desafio que requer mais que experiência, formação.

É nesse sentido que a normalização dos resultados com defasagem de aprendizagem poderiam ser um indicador importante para a modificação/adaptação do plano curricular. Assim as escolas também procedem e isso pode apontar para uma estratégia posterior a ser seguida. Ações planejadas como esta podem implicar em intervenções pontuais por turma/aluno, inclusive como o reforço escolar, assim como planos mais abrangentes e 
consistentes que permeiem todo o Ensino Médio dentro das limitações das realidades de cada escola.

Figura 3: Família Apropriações.

\begin{tabular}{|c|c|c|c|c|c|c|}
\hline & & $\begin{array}{l}\text { Percepção da especificidade } \\
\text { da Escola }\end{array}$ & \multirow{5}{*}{ Estáassociado com } & \multirow{5}{*}{\multicolumn{2}{|c|}{ 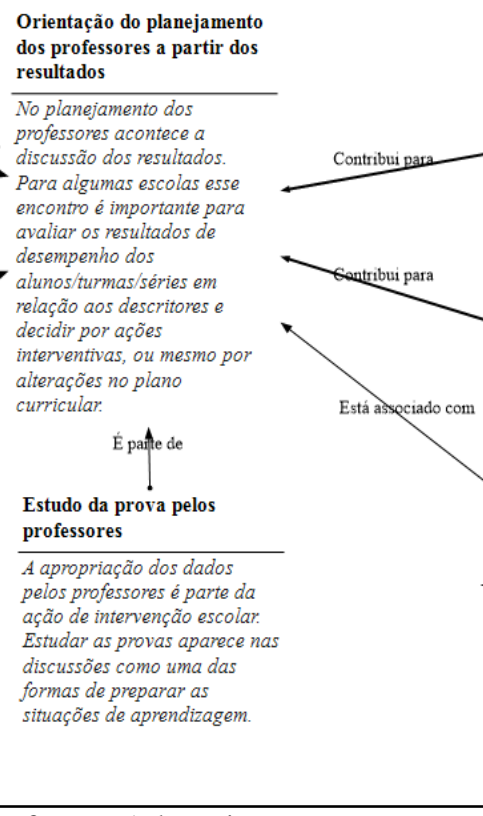 }} & \multirow{2}{*}{$\begin{array}{l}\text { Melhoria na apropriação } \\
\text { pela digitalização dos } \\
\text { resultados } \\
\begin{array}{l}\text { A passagem do modo fisico } \\
\text { para o modo digital do }\end{array} \\
\text { tratamento dos dados facilitou } \\
\text { bastante o trabalho da } \\
\text { coordenação e dos } \\
\text { professores. } \\
\text { Melhoria pela adesão dos } \\
\text { professores }\end{array}$} \\
\hline $\begin{array}{l}\text { Socialização das finalidades } \\
\text { com os alunos }\end{array}$ & & $\begin{array}{l}\text { Os resultados das escolas } \\
\text { também são entendidos de } \\
\text { acordo com os contextos em } \\
\text { que se situam. } \\
\text { Está assoofiado com } \\
\text { Resultados da avaliação } \\
\text { como oportunidade de } \\
\text { melhoria }\end{array}$ & & & & \\
\hline \multirow[t]{3}{*}{$\begin{array}{l}\text { Busca-se a participação dos } \\
\text { alunos inclusive pela } \\
\text { explicação das finalidades da } \\
\text { avaliação. Sendo ainda um } \\
\text { desafio. }\end{array}$} & \multirow[t]{3}{*}{ Requisita } & $\begin{array}{l}\text { Percepção da gestão de que } \\
\text { mesmo resultados } \\
\text { insatisfatórios devem ser } \\
\text { entendidos como uma } \\
\text { oportunidade de direcionar } \\
\text { esforços a fim de melhorar a } \\
\text { aprendizagem dos alunos. } \\
\text { Está assofiado com }\end{array}$ & & & & $\begin{array}{l}\text { A adesão dos professores é } \\
\text { apontada como um ponto forte } \\
\text { para a melhoria na decisão } \\
\text { pelas situaçóes de } \\
\text { aprendizagem. }\end{array}$ \\
\hline & & $\begin{array}{l}\text { Socialização dos dados com } \\
\text { a equipe gestora }\end{array}$ & & & & $\begin{array}{l}\text { A coordenação compartilha os } \\
\text { resultados com os professores. }\end{array}$ \\
\hline & & $\begin{array}{l}\text { A coordenação entra em } \\
\text { contato com os resultaods } \\
\text { pelo site SISEDU e pela } \\
\text { discussão com a } \\
\text { superintendência escolar. }\end{array}$ & & & & \\
\hline
\end{tabular}

Fonte: Elaborado pelos autores com o uso do software Atlas Ti.

A família apropriação compreende as relações que permeiam a tomada de consciência dos resultados da Avaliação Diagnóstica pela equipe gestora e pelos professores. Vianna (2003) aponta que os processos de avaliação contribuem para o professor orientar os procedimentos docentes, sugerir novas estratégias eficientes de ensino, superar problemas curriculares e relacionar contexto social e realidade escolar no sentido de superar suas dificuldades. Percebe-se na figura 3 que esses elementos aparecem no processo de apropriação. É preciso ressaltar que os vários vínculos que se estabelecem entre os códigos indicam uma aproximação técnica com a Avaliação Diagnóstica e com os significados dos seus resultados. Ainda há a implicação da carência formativa acerca dos reais significados que essa aproximação implica, principalmente considerando a necessidade de uma tomada de decisão acerca do que fazer a partir dos resultados. Se isso vai resultar em intervenções pontuais ou em uma mudança de perspectiva que implique em assumir um planejamento curricular que contemple a correção dessas defasagens. 
Figura 4: Família Desafios e dificuldades.

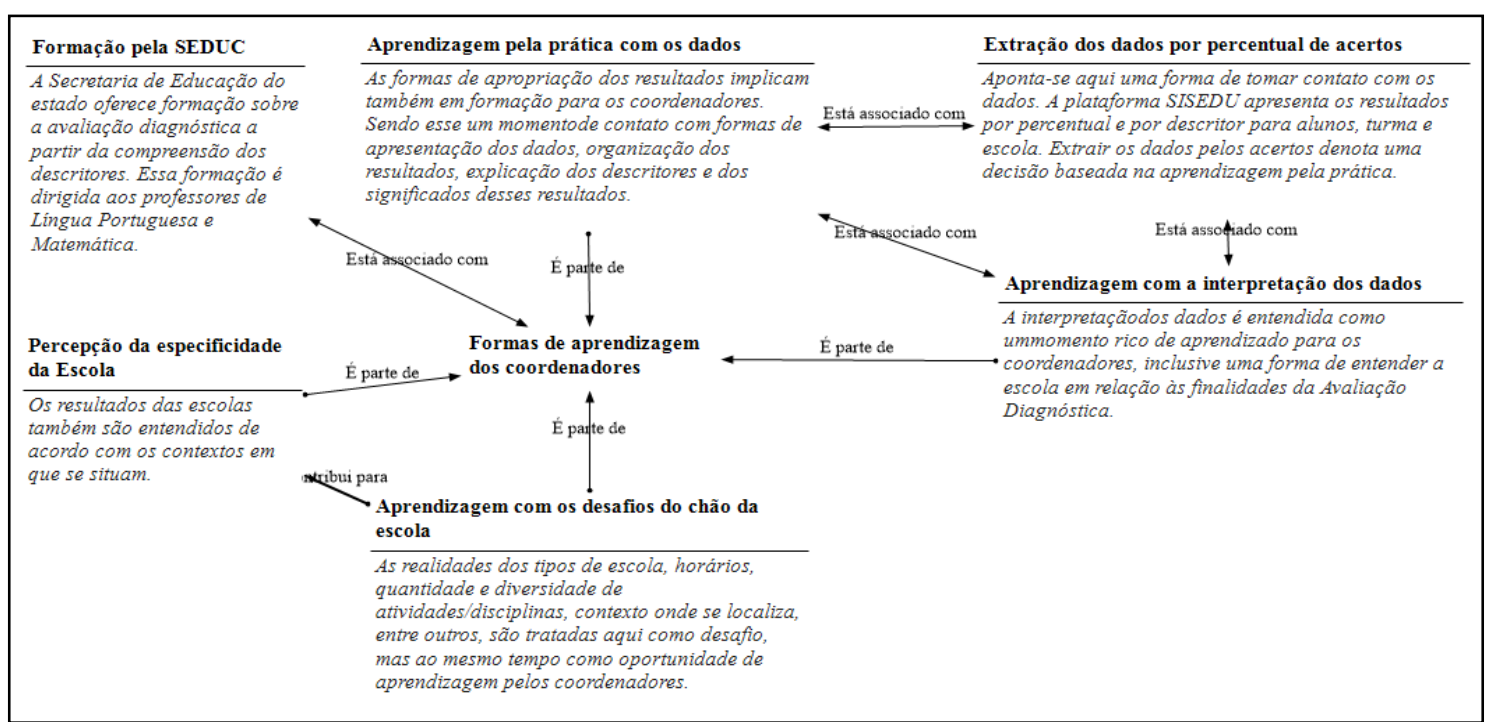

Fonte: Elaborado pelos autores com o software Atlas Ti.

Quanto às dificuldades apresentadas pelos respondentes a carência de recursos para a aplicação da prova em tempo hábil compromete a apropriação dos resultados, tornando mais demorado o retorno e a geração dos materiais estruturados. A quantidade de demandas externas é também considerada um fator que compromete o bom trabalho formativo. Os respondentes também apontaram as carências formativas de professores e de coordenadores como fatores de comprometimento para a compreensão dos resultados e a elaboração de um projeto cujos objetivos de aprendizagem sejam tratados com mais maturidade. 


\section{OO DEVIR EDUCAÇÃO \\ ISSN: 2526-849X}

Fonte: Elaborado pelos autores com o software Atlas Ti.

Figura 5: Formação dos coordenadores

A Avaliação Diagnóstica provoca a mudança de percepção acerca da aprendizagem dos alunos do Ensino Médio através da compreensão das dificuldades de aprendizagem apontadas pelos descritores de proficiência em Língua Portuguesa e Matemática. Ao realizar esse diagnóstico segue-se a apropriação dos resultados pela coordenação escolar. A figura 5 contempla alguns aspectos destacados pelos respondentes sobre a apropriação dos resultados dessa avaliação e sua formação enquanto gestor pedagógico da escola.

As respostas apontam para uma formação que se dá no contato com os dados em relação às realidades escolares com as quais convive. O esforço na interpretação dos dados, a comparação dos resultados com as variáveis externas que influenciam a aprendizagem de seus alunos, a percepção de uma escola mais encravada socialmente nas diversas realidades que a circunscrevem, a aprendizagem pela prática com os dados, tudo isso aponta para uma aprendizagem que é ao mesmo tempo apropriação. Acerca da formação profissional docente Tardif (2014) afirma que os saberes constituídos pelo professor são um saber-fazer que se consolida no cotidiano, onde suas competências são colocadas a prova, que são constituídos no trabalho. Apesar de a avaliação constituir um campo do conhecimento próprio para o professor, e no caso deste trabalho para o coordenador, a prática é o lugar de aprendizagem apontado por estes como sendo o mais profícuo.

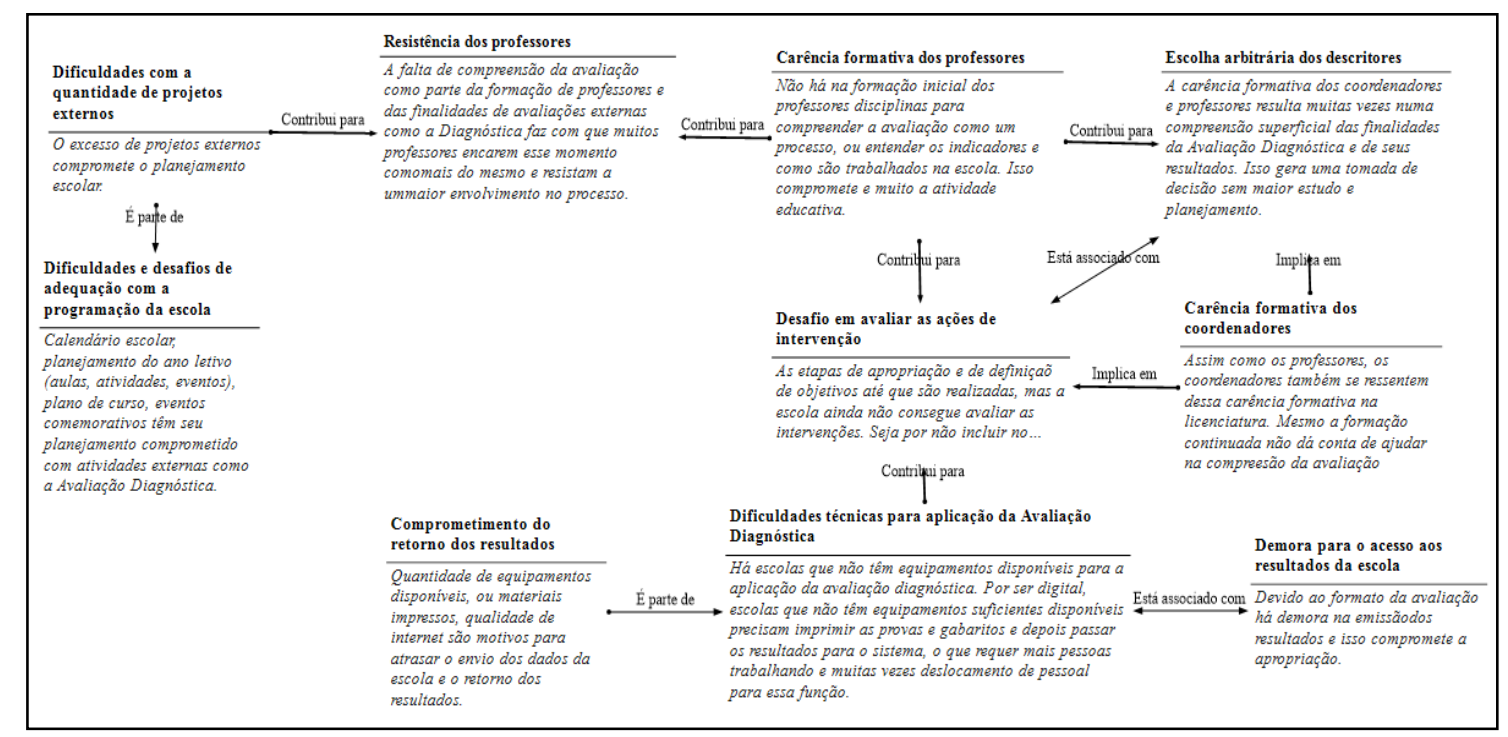

\section{Considerações finais}

Revista Devir Educação, Lavras, vol.5, n2., p.224-248 jul./dez., 2021. 
Ao estudar as finalidades da Avaliação Diagnóstica percebe-se que é uma forma de aproximar os resultados evidenciados pelo SPAECE da escola, numa perspectiva formativa. Essa aproximação requer uma apropriação dos resultados por toda a comunidade escolar de modo a promover uma autoavaliação de cada ator em seu campo de atuação. Este trabalho visou analisar a formação dos coordenadores escolares a partir da apropriação dos dados dessa avaliação numa perspectiva Tyleriana.

Percebeu-se que a aproximação com o objeto a coordenação escolar requer a construção de um corpo de conhecimentos mais robusto que referencie teoricamente suas escolhas para a orientação escolar acerca da proposição de estratégias curriculares que corrijam as defasagens de aprendizagens, visto que ainda há o predomínio da prática nesse ponto, implicando em decisões pautadas em um experimentalismo. Nesse sentido Bachelard aponta a necessidade de uma concepção mais aproximada da ciência que do senso comum. Essa distância que provoca ações mais interventivas que propositivas encontra um desafio na formação inicial de professores, que repercute na apropriação de avaliações como essa, ainda mais considerando que esses professores assumam funções administrativas.

Por outro lado, a Avaliação Diagnóstica fornece dados para que sejam traçadas estratégias para alcançar os objetivos de aprendizagem baseadas nos resultados. Essa relação encontra respaldo em Tyler (1973) que busca, a partir dos resultados da avaliação, impactar a escola com o estudo dos resultados e a elaboração de um plano curricular que atenda às necessidades de aprendizagem dos alunos. Implica também no desenvolvimento de uma cultura de avaliação que proporcione novas aprendizagens e novas iniciativas.

As famílias elencadas na análise das entrevistas apontam para um processo de melhoria da relação com avaliações externas. Acompanhamento, adequação curricular, apropriações, dificuldades e desafios e formação dos coordenadores, que poderia ser substituída por aprendizagem dos coordenadores mostram um percurso desenvolvido pela prática de envolvimento com esses dados na perspectiva da orientação para o desenvolvimento de um plano curricular.

Essa pesquisa aponta para um campo de estudo, a formação dos coordenadores escolares em avaliação que se dá na prática com os elementos administrativos, que pode colaborar com a melhoria dos processos decisórios acerca da aprendizagem escolar.

\section{Referências}

Revista Devir Educação, Lavras, vol.5, n2., p.224-248 jul./dez., 2021. 
ABBAD, G., MOURÃO, L., MENESES, P. P. M., ZERBINI, T., BORGES-ANDRADE, J. E., VILAS-BOAS, R. (Orgs.). Medidas de Avaliação em Treinamento, Desenvolvimento e Educação. Porto Alegre: Artmed, 2012.

ALVES, F.C; SARAIVA; R.S.L. Ralph Winfred Tyler E Os Princípios Básicos Da Avaliação Do Currículo. XII ENCONTRO CEARENSE DE HISTÓRIA DA EDUCAÇÃO. II ENCONTRO NACIONAL DO NÚCLEO DE HISTÓRIA E MEMÓRIA DA EDUCAÇÃO. 2013. Disponível em: 2013_eve_rslsaraiva.pdf (ufc.br). Acesso em 20 jul.2021.

BACHELARD, Gaston.A formação do espírito científico: contribuição para uma psicanálise do conhecimento. Rio de Janeiro: Contraponto, 1996. 316 p.

BRUYNE, Paul de; HERMAN, Jacques; SCHOUTHEETE, Marc de. Dinâmica da pesquisa em ciências sociais: os polos da prática metodológica. Rio de Janeiro: Francisco Alves, 1977.

CAED/UFJF. O SISTEMA: MATRIZ CURRICULAR. In: CAED/UJFJ. MATRIZ CURRICULAR. JUIZ DE FORA-MG: CAED, 2018. Disponível em:

https://spaece.caedufjf.net/o-sistema/matriz-curricular/. Acesso em: 17 jul. 2021

PADRÕES DE DESEMPENHO ESTUDANTIL. In: CAED/UJFJ. PADRÕES DE DESEMPENHO ESTUDANTIL. JUIZ DE FORA-MG, 2018. Disponível em: https://spaece.caedufjf.net/wp-content/uploads/2014/11/SPAECE-RP-LP-EM-WEB1.pdf. Acesso em: 26 jul. 2021.

DE BRUYNE, P.; HERMAN, J.; SCHOUTHEETE, M. de. Dinâmica da pesquisa em ciências sociais: os pólos da prática metodológica. ("Dynamique de La recherche em science sociales") Trad. Ruth Jojjily. Rio de Janeiro: F. Alves, 1977.

DEPRESBITERIS, Léa. Avaliação de programas e avaliação da aprendizagem. In: SOUSA, Eda C. B. Machado de. (Org.). Avaliação de currículos e de programas. 2. ed. Brasília, DF: Editora UnB, 2000.

FERREIRA, Rosilda Arruda, TENÓRIO, Robinson Moreira A construção de indicadores de qualidade no campo da avaliação educacional: um enfoque epistemológico. Revista Lusófona de Educação, 2010, pag. 71-97. Disponível em: https://www.redalyc.org/articulo.oa?id=34915599006 Acesso em 22 jul. 2021.

FRIESE, Susanne. ATLAS.ti 8 Windows: Guia Rápido. [S. 1.: s. n.], 2019. v. 1. Disponível em: http://downloads.atlasti.com/docs/quicktour/QuickTour_a8_win_pt.pdf. Acesso em: 11 jul. 2021.

GREGO, S. M. D. A Avaliação Formativa: Ressignificando Concepções e Processos. In: Universidade Estadual Paulista, Pró-Reitoria de Graduação. (Org.). Caderno de Formação: Formação de professores. Avaliação educacional e escolar. 1. ed. São Paulo: CulturaAcadêmica: Universidade Estadual Paulista, Pró-Reitoria de Graduação v. 3, p. 92110, 2013.

JOSÉ FILHO, Pe. M. Pesquisa: contornos no processo educativo. In: JOSÉ FILHO, Pe. M; DALBÉRIO, O. Desafios da pesquisa. Franca: UNESP - FHDSS, p.63-75, 2006.

LAGE, M. C.; GODOY, A. S. O uso do computador na análise de dados qualitativos: questões emergentes. Revista de Administração Mackenzie, v. 9, n. 4, art. 178, p. 75-98, 
2008.

LIMA, M.A.M. Avaliação de Programas nos Campos da Educação e da Administração: Ideias para um projeto de melhoria ao modelo de Kirkpatrick. REICE - Revista Electrónica Iberoamericana sobre Calidad, Eficacia y Cambio en Educación 2007, Vol. 5, No. 2e. . Avaliação de Programas Educacionais em Organizações: Contrato de Avaliação e Indicadores de Aproveitamento. Editora: UFC. Nave. Fortaleza- 2005.

MARINELLI, M; LIMA, M.A.M. Avaliação De Programas Educacionais — Um Estudo De Caso Na Universidade Corporativa Banco Do Nordeste. Congresso Internacional em Avaliação Educacional. 2010. p. 1716 - 1743. ISBN 978-85-89872-75-1

MACIEL, I.M.O. Avaliação de programas de educação profissional: estudo em organizações do sistema "s". Dissertação. 174 p. Universidade Federal do Ceará, 2009.

PENHA, Rodolfo Sena da et al. SISEDU: Sistema Online de Avaliação, Suporte e Acompanhamento Educacional. Anais dos Workshops do Congresso Brasileiro de Informática na Educação, [S.1.], p. 1124, nov. 2019. Disponível em: <https://brie.org/pub/index.php/wcbie/article/view/9066>. Acesso em: 29 jul. 2021. doi:http://dx.doi.org/10.5753/cbie.wcbie.2019.1124.

SERAPION, M. Conceitos e métodos para a avaliação de programas sociais e politicas publicas. Sociologia. Revista da Faculdade de Letras da Universidade do Porto, Vol. XXXI, 2016, pág. 59-80.

TYLER, Ralph W. PRINCIPIOS BASICOS DEL CURRICULO. 1. ed. BUENOS AIRES AR: EDITORA TROQUEL S/A, 1973. 131 p.

TYLER, Ralph W. Princípios básicos do currículo e ensino. $3^{\text {a }}$ Ed. Tradução de Leonel Vallandro. Porto alegre: globo, 1976.

Recebido em: setembro/2021. Aprovado em: novembro/2021. 